\title{
Response from Varani et al. to "Comment on 'the IS6 family, a clinically important group of insertion sequences including IS26' by Ruth M. Hall"
}

\author{
Alessandro Varani ${ }^{1}$, Susu He ${ }^{2}$, Patricia Siguier ${ }^{3}$, Karen Ross $^{4}$ and Michael Chandler ${ }^{5^{*}}$
}

\begin{abstract}
The IS6 family of insertion sequences is a large but coherent group which was originally named to avoid confusion between a number of identical or nearly identical IS that were identified at about the same time and given different names (IS15D, IS26, IS46, IS140, IS160, IS176). The underlying common mechanistic feature of all IS6 family members which have been investigated is that they appear to transpose by replicative transposition and form pseudo compound transposons with the flanking IS in direct repeat and in which associated genes are simply transferred to the target replicon and lost from the donor.

In the accompanying letter Hall raises a number of very serious and wide-ranging criticisms of our recent review article concerning the IS6 family of insertion sequences. She clearly feels that we have undervalued her work and that we question or ignore certain of her in vivo results. This impression is almost certainly the result of the standard of proof we generally apply to mechanistic aspects of transposition where we think it important to identify transposition intermediates including the types of synaptic, strand cleavage and strand transfer complexes involved.
\end{abstract}

\section{Background}

Hall raises a number of serious and wide-ranging criticisms of our review article [1] (see also https://tnpedia. fcav.unesp.br/index.php/IS_Families/IS6_family) that we: 1) "seriously misrepresented" her work with Harmer; 2) failed to take into account her data [2]; 3) "incorrectly implied that any mechanism established for IS26 can be assumed to apply to a range of IS that are at best very distantly related" and 4) that "questioned the existence of translocatable unit (TU)". It was not our intention to question her results. We apologise if she has interpreted our text in this manner and are grateful for her exquisitely detailed and rigorous inspection of our review.

\section{Main text}

1) It was certainly not our intention to wilfully misrepresent Hall's data - which include excellent and incisive experiments and analyses. The impression that she has, merely reflects the fact that we have been consistently prudent and cautious in our interpretation of in vivo transposition data until such time as the intermediates in the process, in this case of conservative integration, have been identified. This can be seen in other IS family chapters of TnPedia (https://tnpedia.fcav.unesp.br/index.php/IS_Famil ies [3];). It is especially important in cases where new mechanisms are proposed. Our standard of 
proof would entail identification of the types of synaptic, strand cleavage and strand transfer complexes involved, which could be accessed either from in vivo or in vitro studies but at present these are not available.

2) We acknowledge that one reference from the large body of Hall's IS26 work is missing: [2] (reference (6) in Hall's letter) for which one of us, MC, had already apologised in personal correspondence. Reference (2), indeed, presents evidence that targeted integration does not require both IS ends, raising the possibility that the potential intermediate (Fig. 11 iii), (https://tnpedia.fcav.unesp.br/index.php/File:FigIS6. 14.png) could be resolved in a number of different ways (replication, Holiday junction resolution etc.) as we have clearly stated (page 13,right column, lines 40-41) "The authors propose a model in which a single IS end is cleaved and transferred to the flank of the target IS end, an event which creates a Holliday junction, which, on branch migration, is resolved". This further underlines the importance of directly identifying intermediate structures in confirming the proposed mechanism.

3) Concerning the IS family definition and its relation to mechanism: In developing ISfinder (https://wwwis.biotoul.fr/index.php) and, more recently, TnPedia (https://tnpedia.fcav.unesp.br/index.php/Main_Page) and TnCentral [3], we have always adhered to the principle that, in addition to sequence similarities, members of a given family generally share a common basic transposition mechanism (defined in [4] and https://tnpedia.fcav.unesp.br/index.php/Gener al_Information/IS_Identification). In the case of all IS6 family members investigated thus far [1], that common feature appears to be replicative cointegrate formation and the formation of pseudo compound transposons [5] with the flanking IS in direct repeat in which associated genes are simply transferred to the target replicon and lost from the donor [5]. We did not mean to imply that the entire IS6 family also possess the mechanistic variation proposed by Hall (i.e., targeted conservative integration). That has clearly yet to be addressed. Consequently, to continue to provide a consistent structural framework for understanding the relationship between the nearly 6000 IS in the ISfinder database, we continue to adhere to these rules and include IS26 and close relatives as a sub-group within the IS6 family.

4) We are surprised Hall feels that "Varani et al. also question the existence of TU", especially since we conclude that "the notion that the basic IS6 family transposition unit is a non-replicative circular DNA molecule carrying a single IS copy is attrac- tive and would provide a nice parallel to the integron antibiotic resistance gene cassette intermediates". And also state that "To summarize: it has been clearly demonstrated that circular DNA species carrying a single IS26copy together with flanking "passenger" DNA can be generated efficiently in vivo from a variant plasmid replicon [116] and also that replicons carrying a single IS26 copy are capable of integrating into a second replicon to form a cointegrate." We are of the opinion that Harmer et al., have provided considerable evidence for TU (which we inadvertently called "transposable unit" in 2 figures rather than Hall's "translocatable unit" used in our text). However, again, we express caution in our review because, as yet, there is no firm biochemical data bearing on this interesting and attractive model.

\section{Conclusion}

To understand the true relationship between different members of the IS6 family and their transposition mechanism(s), it will be essential to extend studies to other family members, particularly those with additional transposase domains (https://tnpedia.fcav.unesp. br/index.php/File:FigIS6.7.png), and to identify physically and biochemically intermediated in their transposition pathways.

\section{Authors' contributions}

The author(s) contributed to writing the manuscript, read and approved the final version.

\section{Declarations}

\section{Competing interests}

The authors declare that they have no competing interests.

\section{Author details}

${ }^{1}$ School of Agricultural and Veterinary Sciences, Universidade Estadual Paulista, Jaboticabal, Sao Paulo, Brazil. ${ }^{2}$ State Key Laboratory of Pharmaceutical Biotechnology, Medical School of Nanjing University, Nanjing 210093, Jiangsu, China. ${ }^{3}$ Centre de Biologie Intégrative-Université Paul SABATIER, CNRS - Laboratoire de Microbiologie et Génétique Moléculaires, UMR 5100 - bât. CNRS-IBCG, Toulouse, France. ${ }^{4}$ Department of Biochemistry, Molecular and Cellular Biology, Protein Information Resource, Georgetown University Medical Center, Washington, DC, USA. ${ }^{5}$ Department of Biochemistry, Molecular and Cellular Biology, Georgetown University Medical Center, Washington, DC, USA.

Received: 7 October 2021 Accepted: 4 November 2021

Published online: 03 January 2022

\section{References}

1. Varani A, He S, Siguier P, Ross K, Chandler M. The IS6 family, a clinically important group of insertion sequences including IS26. Mob DNA. $2021 ; 12: 11$ 
2. Harmer CJ, Hall RM. Targeted conservative formation of cointegrates between two DNA molecules containing IS26 occurs via strand exchange at either IS end. Mol Microbiol. 2017;106:409-18.

3. Ross K, Varani AM, Snesrud E, Huang H, Alvarenga DO, Zhang J, et al. Tncentral: a prokaryotic transposable element database and web portal for transposon analysis. MBio. 2021;12:e0206021.

4. Siguier P, Gagnevin L, Chandler M. The new IS1595 family, its relation to IS1 and the frontier between insertion sequences and transposons. Res Microbiol. 2009;160:232-41.

5. Galas DJ, Chandler M. Bacterial insertion sequences. In: Berg DE, Howe MM, editors. Mobile DNA. Washington, D.C.: American Society for Microbiology; 1989. p. 109-62.

\section{Publisher's Note}

Springer Nature remains neutral with regard to jurisdictional claims in published maps and institutional affiliations.

- fast, convenient online submission

- thorough peer review by experienced researchers in your field

- rapid publication on acceptance

- support for research data, including large and complex data types

- gold Open Access which fosters wider collaboration and increased citations

- maximum visibility for your research: over $100 \mathrm{M}$ website views per year

At BMC, research is always in progress.

Learn more biomedcentral.com/submissions 